\title{
BMJ Open Parental assessment of disease severity in febrile children under 5 years of age: a qualitative study
}

Dora L Kuijpers, ${ }^{1}$ Daphne Peeters (D) , ${ }^{1}$ Nina C Boom, ${ }^{2}$
Josephine van de Maat (D) , ${ }^{3,4}$ Rianne Oostenbrink (D), ${ }^{4}$ Gertjan J A Driessen ${ }^{1,5}$

To cite: Kuijpers DL, Peeters D, Boom NC, et al. Parental assessment of disease severity in febrile children under 5 years of age: a qualitative study. BMJ Open 2021;11:e042609. doi:10.1136/ bmjopen-2020-042609

- Prepublication history and additional materials for this paper are available online. To view these files, please visit the journal online (http://dx.doi. org/10.1136/bmjopen-2020042609).

Received 14 July 2020

Revised 23 December 2020

Accepted 21 January 2021

Check for updates

(c) Author(s) (or their employer(s)) 2021. Re-use permitted under CC BY-NC. No commercial re-use. See rights and permissions. Published by BMJ.

${ }^{1}$ Department of Paediatrics, Juliana Children's Hospital, The Hague, The Netherlands ${ }^{2}$ Department of Paediatric Intensive Care, Leiden University Medical Center, Leiden, The Netherlands

${ }^{3}$ Infectious Diseases and Global Health, Radboudumc, Nijmegen, The Netherlands

${ }^{4}$ General Paediatrics, Erasmus MC Sophia Children's Hospital, Rotterdam, The Netherlands

${ }^{5}$ Department of Paediatrics, Maastricht University Medical Center+, Maastricht, The Netherlands

Correspondence to Dr Gertjan J A Driessen; gertjan.driessen@mumc.nl

\section{ABSTRACT}

Objective To explore how parents judge disease severity of their febrile child and to identify symptoms they associate with serious illness, minor illness or health. Design Semistructured interviews were conducted. Interviews were audio taped, transcribed verbatim and analysed thematically.

Participants Parents of children aged $0-5$ years with a febrile illness.

Setting Participants were recruited at the paediatric ward and the emergency department.

Results Twenty-six interviews were conducted, in which 37 parents participated. Parents described disease severity of their child mainly in terms of changes in their child's normal characteristics (behaviour and physical features). They found it harder to describe specific disease symptoms such as dyspnoea or dehydration. Their child being active, eating and drinking well, and smiling were perceived as reassuring, whereas high fever, moving very little and uncertainty about the type of infections were mentioned as alarming symptoms. Previous experience with febrile illnesses in their children was of great influence on the number and accuracy of symptoms they reported.

Conclusion Parents used the normal behaviour and physical features of their child as a reference frame for judging disease severity. With a larger deviation from the child's normal characteristics, parents considered the illness more serious. They were less able to describe specific symptoms of disease such as dyspnoea or dehydration. This knowledge is important for clinicians in their communication with parents of children with febrile illness.

\section{INTRODUCTION}

Febrile illnesses are very common in children. Preschool children experience almost two infectious diseases per year. ${ }^{1}$ In Western Europe, in 20\%-39\% of children with fever a doctor is consulted ${ }^{2}{ }^{3}$ and about half of the consultations on the paediatric emergency department (ED) are for infections. ${ }^{4}$ The majority of these children have a viral infection, which requires little or no medical intervention. Only $10 \%-15 \%$ of the children with febrile illness at the ED have a serious

\section{Strengths and limitations of this study}

- This study presents an integral overview of what parents take into account when assessing disease severity in their child.

- Because of the in-depth interviews, we were able to explore not only alarming symptoms, but also signs that reassure parents.

- The qualitative study design enabled us to explore the parents' perspective thoroughly.

- This study did not examine the correlation between parent-reported symptoms and disease severity as judged by health professionals and/or diagnostic tests.

- Because this study was performed on the paediatric emergency department with parents without a severe language barrier, its main limitation is the generalisability to other settings such as primary care or parents with limited understanding of the Dutch language.

bacterial infection. ${ }^{5}$ However, it is essential to distinguish serious infections from minor infections to reduce morbidity and mortality. Recognition of disease severity by parents and subsequent healthcare-seeking behaviour of parents are the first steps in this process.

Because of the low prevalence of severe disease and abundance of mild disease, diagnosis of serious infections in febrile children is challenging. ${ }^{6}$ In the treatment guideline for febrile children at the ED in the Netherlands, ${ }^{7}$ which is largely based on the National Institute for Health and Care Excellence guideline for fever, the main factors that are taken into account are the doctors' observations and laboratory tests. However, it would be very useful to acquire a greater understanding of the parental perspective of disease severity assessment as the first step in the diagnostic process. Parents are capable of identifying their child as ill ${ }^{89}$ and the parental instinct for disease is an indicator for disease severity. ${ }^{6}$ However, what parents take into account exactly while judging disease severity 
and what symptoms they can recognise in their child are largely unknown.

Therefore, the aim of this study is to explore how parents judge disease severity in their febrile child. In particular, which signs and symptoms parents associate with severe illness, which conditions they associate with a healthy state and the spectrum in between these limits.

\section{METHODS}

\section{Study design}

We performed a qualitative study with semistructured interviews in order to explore how parents judged the severity of illness of their febrile child. A topic guide for semistructured interviews (online supplemental file 1) was developed based on the study objective, existing literature, clinical experience and the Dutch treatment guideline to assess febrile children in hospital setting. ${ }^{7}$ The content and phrasing of the questions were reviewed by experts in paediatrics and adjusted in accordance with their remarks.

\section{Recruitment}

A sample of parents of children with fever aged 1 month-5years was recruited. We aimed to obtain maximum variation within the sample in terms of patient age and the experience of parents with diseases in their children. Recruitment took place at the Haga Teaching Hospital, Juliana Children's Hospital in the Hague (the Netherlands), on both the paediatric ED and the paediatric ward. Parents were interviewed at times the medical staff did not need to attend the patient, for example, during waiting time for lab results. Both at the ward and at the ED, the average interview duration was $20 \mathrm{~min}$. Recruitment was continued until data saturation occurred. Parents with children were included if fever $\left(>38.0^{\circ} \mathrm{C}\right)$ was reported during the illness episode or if a fever was measured in the hospital. Parents of patients with a life-threatening condition that needed immediate medical attention were excluded. Another exclusion criterion was a severe language barrier, defined as parents not being able to understand the participant information folder and not able to communicate sufficiently with the study team.

\section{Data collection and analysis}

Semistructured interviews were conducted in April and May 2019. The interviews with the parent(s) took place at the patient's room at the ED or ward. Participants were enrolled after providing written informed consent. Interviews were audio recorded and transcribed verbatim by the first author (DLK), including non-verbal information. After 18 interviews, a preliminary analysis took place in the study team, which guided in-depth questions for the subsequent interviews. Data saturation occurred after 26 interviews. The accuracy of transcripts was verified by comparing them with the original audio fragments by NCB. Thematic analysis was conducted using MAXQDA data management system. ${ }^{10}$ The transcripts were independently read thoroughly by DLK and NCB. Thereafter codes were identified inductively by both investigators in eight transcripts, after which they compared the codes and edited the codes until consensus was reached. The codes were grouped into themes. Conceptual links were visualised in figures by DLK, NCB and GJAD.

\section{Patient and public involvement}

Patients or parents were not involved in the design of this study. However, our study aim and design was completely focused on retrieving their perspective. The results of this study (parent-reported disease severity) can help paediatricians for improving their communication with parents of children with febrile illnesses.

\section{RESULTS}

\section{Demographics}

Twenty-six interviews were conducted, in which 37 parents participated: 24 mothers and 13 fathers. In 11 interviews, both parents were present and in 15 interviews only one of them attended. Three eligible parents decided not to participate, out of privacy reasons (one) and lack of time (two). Detailed participant characteristics are presented in table 1.

\section{Main themes}

The following themes emerged from the data:

- Judgement of disease severity using the child's normal characteristics.

- General illness signs recognised by parents.

- Difficulty of describing specific symptoms of disease.

- Factors influencing parents' ability to assess disease severity.

\section{Judgement of disease severity using the child's normal characteristics}

The child as its own reference

In all interviews, parents reported to recognise disease from their child's characteristics being different from normal. They mentioned subtle differences on various characteristics, including behaviour, like activity level and mood, and physical features, like temperature and appearance. Parents stated to use their child's normal characteristic being the reference for recognising disease: 'Every day and night we are with the kids. So you know how your child behaves normally. And everything that deviates from that, is an indication [of disease] for me.' (Mother, patient 1 year). Online supplemental file 2 provides an overview of all relevant quotes. Also see quotes 2-3 (Q2-3).

Parents with multiple children described that signs of febrile disease differed greatly between siblings, which depended on the child's normal characteristics. Every child has specific characteristics which parents use to recognise (severe) disease: 'He [patient's brother] is always calm and you would see that he becomes more 
Table 1 Baseline data of interviewed parents $(\mathrm{N}=37)$ and their child with fever $(\mathrm{N}=26)$

\begin{tabular}{|c|c|}
\hline Patient's age in years & $1.9(0-5)$ \\
\hline Child's sex, male & $46 \%(12)$ \\
\hline \multicolumn{2}{|l|}{ Country of birth, child } \\
\hline The Netherlands & $100 \%(26)$ \\
\hline Parents' age in years & $34(26-48)$ \\
\hline Total number of parent's children & $2(1-4)$ \\
\hline \multicolumn{2}{|l|}{ Education level of the interviewed parents* } \\
\hline Low & $5,4 \%(2)$ \\
\hline Middle & $46 \%(17)$ \\
\hline High & $49 \%(18)$ \\
\hline \multicolumn{2}{|l|}{ Country of birth, interviewed parents } \\
\hline The Netherlands & $65 \%(24)$ \\
\hline Suriname & $8,1 \%(3)$ \\
\hline Turkey & $5,4 \%(2)$ \\
\hline Morocco & $5,4 \%(2)$ \\
\hline Other† & $16 \%(6)$ \\
\hline Mother present at interview & $92 \%(24)$ \\
\hline Father present at interview & $50 \%(13)$ \\
\hline Mother and father present at interview & $42 \%(11)$ \\
\hline Interviews in acute setting (ED) & $46 \%(12)$ \\
\hline Patient admitted after interview at ED & $33 \%(4)$ \\
\hline Interviews in non-acute setting (ward) & $54 \%(14)$ \\
\hline $\begin{array}{l}\text { Number of previous hospital admissions of all } \\
\text { of the parent's children } \ddagger\end{array}$ & $1(0-41)$ \\
\hline \multicolumn{2}{|l|}{$\begin{array}{l}\text { Number of hospital presentations (ED or } \\
\text { outpatient clinic) with all of the parent's } \\
\text { children }\end{array}$} \\
\hline 1 time & $12 \%(3)$ \\
\hline $2-5$ times & $42 \%(11)$ \\
\hline$>5$ times & $46 \%(12)$ \\
\hline
\end{tabular}

Categorical variables are displayed as a number with percentage, continuous variables as a median with range.

*Education levels are based on the classification of Statistics Netherlands. ${ }^{26}$

†Netherlands Antilles, Dominican Republic, Syria, Colombia, Pakistan, Germany.

‡Data not available for four children.

ED, emergency department.

quiet because he is drowsy and passive [...] He becomes quiet with fever, unlike him [patient]. He [brother] would be quiet and sit in a corner and he [patient] would be crying very loudly, like: hey, I'm not feeling well!' (Father, patient 1 year).

\section{Parental instinct}

In 13 of the 26 interviews, parents mentioned to notice that something was wrong with their child based on their parental instinct. This instinct was regularly expressed in combination with recognising that something was abnormal in their child; there seems to be overlap between the parental instinct and recognising differences in their child's characteristics: Father: 'Yeah, we just notice it as a parent! I don't know. He's just really a different child [if he's ill]. Maybe it's based on the parent's instinct.' Mother: '[...] What they normally find interesting, is suddenly not interesting anymore! Then you instantly notice that there is something wrong.' (patient 3 years).

In six interviews, parents spontaneously reported that the mother's instinct was stronger than the father's instinct, and that mothers were therefore better in evaluating the severity of disease. As a reason for the mother's instinct being very strong was that mothers said to know their child better. Father: 'And your intuition [to mother] is even stronger than mine. [...] I think that's the widely known mother's instinct. [...] I really keep an eye on him, but what you have... That is just an extra sensor which is turned on!' (patient 6 months) (also see Q7, online supplemental file 2).

\section{General illness signs \\ General signs}

Parents mentioned a broad range of signs and symptoms to describe the abnormal state of the child in case of disease. Table 2 shows reassuring, general and alarming signs of disease from the parents' perspective on all aspects of their child's characteristics. All signs were present in both children under 1 year old and in older children.

In all interviews, parents described their child suffering from febrile illness as being in a less energetic state, in which the child ate less, drank less, urinated less, played less and slept more than normal. In four interviews parents described that disease could also be recognised if their child was hyperactive, irritable, in a bad mood and nagging (Q8-9, online supplemental file 2). Besides this less energetic mental or physical state, parents reported to recognise disease from changes in the child's appearance. The child would be pale, warm and sweaty, or would have red cheeks (with fever). Parents reported also to recognise disease from 'the look in their eyes' (Q10-11, online supplemental file 2 ).

\section{Alarming signs}

Parents described that the less energetic state in case of febrile illness would get worse with increased disease severity. In severe disease it would alter to a state in which the child barely eats or drinks, is very weak, and/or barely responds to social stimuli and/or sleeps a lot (table 2 and Q12-13 in online supplemental file 2).

Still, there were major differences in what parents considered alarming, which was linked to their previous experiences with health and disease. Signs that parents of relatively healthy children considered alarming were considered as less alarming by parents of children with a relevant medical history. For example, there was a parent of a relatively healthy child who appraised being passive as an alarming sign, whereas a parent of a child with an extensive medical history described being passive 
Table 2 Signs and symptoms that are recognised/reported by parents

\begin{tabular}{|c|c|c|c|}
\hline Characteristic & Reassuring (normal) & General illness (abnormal) & Alarming (very abnormal) \\
\hline Activity & Walking (crawling), being active & Having less energy, being passive & $\begin{array}{l}\text { Not doing anything at all, being very } \\
\text { weak }\end{array}$ \\
\hline $\begin{array}{l}\text { Eating and } \\
\text { drinking }\end{array}$ & Eating and drinking well & Eating and drinking less & $\begin{array}{l}\text { (Almost) not drinking and eating } \\
\text { anymore }\end{array}$ \\
\hline Sleeping & Sleeping as much as normal & Sleeping more or restlessly & $\begin{array}{l}\text { Sleeping extremely much or very } \\
\text { restlessly }\end{array}$ \\
\hline Consciousness & Alert & Being slow or absent & Not waking up, being delirious \\
\hline Mood & Happy, smiling & Not smiling, not happy & Crying continually \\
\hline Talking & Talking (babbling) & Being more quiet & Not talking or babbling anymore \\
\hline Responding & $\begin{array}{l}\text { Responding normally to social cues } \\
\text { or recognising parent }\end{array}$ & Responding slower or less & $\begin{array}{l}\text { (Almost) not responding anymore, } \\
\text { not recognising parent, not making } \\
\text { contact }\end{array}$ \\
\hline Temperature & No fever or temperature decreases & Fever $\left(>38^{\circ} \mathrm{C}\right)$ & High fever $\left(>40^{\circ} \mathrm{C}\right)$ \\
\hline Paracetamol & $\begin{array}{l}\text { Good effect of paracetamol on } \\
\text { temperature and behaviour }\end{array}$ & & $\begin{array}{l}\text { No effect of paracetamol on } \\
\text { temperature and behaviour }\end{array}$ \\
\hline $\begin{array}{l}\text { Cause of } \\
\text { disease }\end{array}$ & $\begin{array}{l}\text { Clear cause, recognising harmless } \\
\text { disease, course of disease like } \\
\text { expected }\end{array}$ & & $\begin{array}{l}\text { Unclear which disease, recognising } \\
\text { serious disease from earlier }\end{array}$ \\
\hline
\end{tabular}

Characteristics mentioned in at least eight interviews are represented in italics. There was some overlap in what parents considered as illness signs and alarming signs. There was no overlap between reassuring signs and illness signs. This is symbolised by the coloured rectangle and arrow.

as a general sign to recognise febrile illness. 'Actually she always stays a bit active. If she would get passive, I would worry. I have only experienced that once, maybe.' (Mother, patient 4 years, no significant medical history); 'Then he gets lethargic or he starts being delirious, he sees things that are not there. But then he really has a high fever. [...] Look, if he has a fever and he is totally 'out', and he is barely moving, being weak... Yeah, then I am really worried.' (Mother, patient 5 years, significant medical history). Signs that experienced parents considered alarming were extreme weakness, lethargy, delirium, not responding well or being unable to wake their child.

\section{Reassuring signs}

Parents considered it reassuring if the less energetic state had disappeared or had not occurred at all. They found it reassuring if the child's characteristics (physical features and behaviour) had returned to what was normal for the child (table 2 and Q16-17 in online supplemental file 2).

The complete picture

Parents explained that they assessed disease severity based on the whole picture of alarming and reassuring signs (Q18). For example, in the case of high fever also other aspects of the child's normal characteristics would be assessed to judge disease severity: 'Only if it [fever] is very high, and I see that the kid is not well, then I instantly want to call the GP or out-of-hours services. But if he is playing a lot, eating, drinking, with the fever, then it's no problem if it's 40 degrees. Then I just wait 3 days. [...] I know it when my child is sick or not: I see that he doesn't play, eat, drink or pee anymore, has difficulties with peeing, or has red dots. Or if he is restless, then I know that something is wrong with him.' (Mother, patient 9 months).

Additionally, symptoms of children with a relevant medical history were interpreted in a different way; parents were more cautious about severe disease (or a relapse of severe disease) in these children depending on previously experienced specific signs or symptoms for this disease 'If [name older brother] has a fever, you think: well, it's only the flu. And he is not sick very often. [...] But look, with [name patient], because of his condition... With him that's the moment to go to the hospital. To [name older brother] I would say: just stay at home, I will put a blanket on you, just wait 'till it's over.' (Mother, patient 5 years). 


\section{Difficulty of describing specific symptoms of disease}

Previous experience was important in recognising specific symptoms. The majority of the interviewed parents had no experience with certain symptoms like dehydration or dyspnoea. These parents found it harder to describe how they could recognise these specific conditions.

Regarding dyspnoea, parents stated in 10 interviews that they did not know what the symptom presentation looked like. Seven of them tried to imagine what it would look like: 'Eh, he has never really had that. But I can imagine: high chest breathing, located here [points high on the chest].' (Mother, patient 5 years) (see also Q21, online supplemental file 2). Parents who had recent experience with their child being short of breath, could describe very precisely how they could recognise this symptom: 'If he is short of breath, then he's only coughing. He becomes red and sweaty. And he breathes very quickly. [...] Sometimes his lungs are also wheezing. A wheezing sound is coming out of them.' (Mother, patient 4 years) (see also Q24, online supplemental file 2).

Regarding dehydration, parents mentioned in 15 interviews that they could recognise dehydration from the fluid balance in the child's body: a relative higher fluid loss compared with the fluid gains. In six interviews, parents had no clue how to recognise it (Q25-26, online supplemental file 2).

\section{Factors influencing parents' ability to assess disease severity}

Three major factors influence the parents' ability to assess disease severity: previous experience with signs and symptoms, knowing the child's normal characteristics and the child's ability to speak (see figure 1).

\section{Experience with previous illness}

Previous experience with disease influences the parents' capability of recognising diseases and judging disease severity (Q27, online supplemental file 2). Accordingly, the capability of assessing disease severity increased when
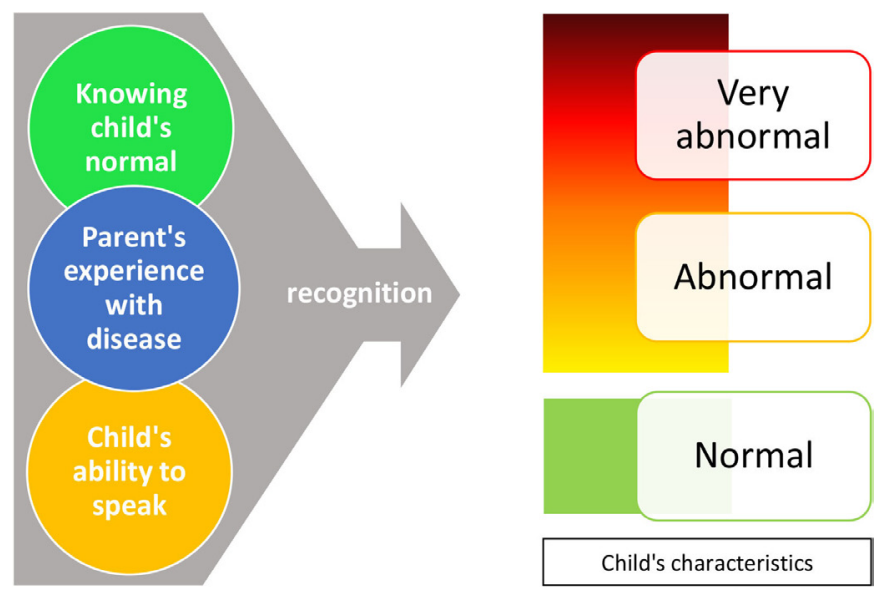

Figure 1 The concept of the parent's ability to recognise symptoms for disease severity assessment. At the left, we grouped elements that influenced parental ability to describe symptoms. Child's characteristics (as described in table 2) are schematically represented at the right. parents had more children and when the child got older (Q28, online supplemental file 2).

\section{Knowing your child}

Parents also described that they had to know their child well to be able to recognise illness signs. They explained that this was harder in young infants. Knowing the child very well enabled them to recognise subtle changes in their child's normal characteristics: Mother: 'Especially the first few weeks were quite difficult. Because then you don't understand the different cries well: is she hungry now or is she just tired? You just don't know that well enough. [...].' Father: 'At some point just know better what's right and what's wrong.' Mother: 'Yeah, you get to know your child better.' (patient 2 months).

\section{Ability to speak}

Parents expressed that assessing disease severity was easier in older children because they were able to talk. Parents felt insecure about their interpretation of the symptoms if the child was not yet able to express himself or herself (Q30-31, online supplemental file 2).

\section{DISCUSSION}

This study presents an integral perspective regarding parental judgement of disease severity in their febrile child. Parents mainly used the normal characteristics in terms of behaviour and physical features of their child as a reference frame for interpreting signs and symptoms of disease. Parents could describe alterations in the normal characteristics of their children very precisely, but were less able to describe specific symptoms for disease such as dyspnoea or dehydration if they had no previous experience with these conditions. The variety of illness signs parents described was mainly dependent on their previous experience with disease, as well as the child's ability to speak and how good the parent knew the child's normal characteristics.

A strong point of our study is to provide an overview of how parents assess disease severity in their febrile child. Various studies have described what parents considered alarming signs but there are no studies that showed the complete spectrum from reassuring to alarming signs and symptoms from the parental perspective. The alarming signs described in the literature support our findings, as they are similar to the alarming signs we found. ${ }^{11-20}$ All alarming signs were alterations of the normal characteristics of their child, like crying differently, being weak, drinking or eating less. Specifically, van der Werf et $a l^{14}$ described that parents judged disease as severe based on behavioural changes, whereas clinicians based this mainly on specific symptoms and physical examination. This is supported by our data that parents mainly focused on abnormalities in relation to their child's normal characteristics instead of specific symptoms in disease severity assessment. This also underlines the importance of investigating how parent-reported symptoms could be used in 
the physician's disease severity assessment and communication with parents.

Some studies have investigated the association between parent-reported disease severity and physician-reported disease severity. The parents' feeling that the ongoing disease episode is different from common disease episodes is a very strong predicting factor for severe disease. ${ }^{21}$ However, the evidence for the predictive value of other parent-reported symptoms for disease severity is scarce, like reduced eating or drinking, sleep disturbance or change in cry, ${ }^{22-25}$ and the evidence of the predictive value of parent-reported respiratory symptoms like coughing is ambiguous. ${ }^{22}{ }^{23}$ Interestingly, one of these studies found a poor agreement between observations of parents and medical staff regarding dyspnoea. ${ }^{23}$ This difference can be explained by our observation that most parents were not able to recognise and describe dyspnoea well, except for parents with previous experiences with dyspnoea.

Another strength of this study is the design; the qualitative study design enabled us to explore the parents' perspective thoroughly. The interview atmosphere was open and the researchers had no influence on the child's medical care, reducing the risk of social desirability bias. The exclusion of parents with a severe language barrier could be a limitation of this study, because it could affect the generalisability of the results. However, parents with a moderate language barrier were included and overall the participant group was diverse in terms of age, cultural backgrounds and experience with disease. Parents with a lower socioeconomic status were under-represented in our study. Additionally, the research was performed in a hospital and ED setting, not in general practitioner (GP) setting. In the Dutch ED, most patients are referred by a GP, which makes the a priori risk of serious infection in children with fever higher. Therefore, the generalisability of the results is restricted to a hospital setting.

Our findings are relevant for clinical practice. Increasing awareness of the way parents recognise disease severity of their child may improve the communication between parents and physicians. Physicians should be aware that parents notice minor behaviour changes in their child because they compare this to the child's normal characteristics. Medical staff would not notice these differences easily. In contrast, specific symptoms of diseases like dyspnoea or dehydration could be more difficult to recognise by parents without previous experience with these symptoms. This underlines the importance of clear discharge instructions, which should be straightforward and unambiguous. During telephone consultations, in particular-a frequently used form of follow-up after discharge-all medical staff should keep in mind that specific disease symptoms could be hard to recognise and interpret by parents. We suggest to transform our table 2 into a checklist of items to be of use in routine practice that parents are able to recognise in his/her child. In the same way, clinicians can use the list as a basis for postdischarge follow-up.
The predictive value of parent-reported symptoms in relation to disease severity is still largely unknown. Further research should therefore explore the diagnostic value and applicability of parent-reported symptoms. Next, it is important to prove a correlation between parentreported symptoms and disease severity as judged by health professionals and/or diagnostic tests. If so, parentreported disease severity could be used to predict disease severity in the prehospital phase as well as during postdischarge follow-up of febrile children (safety netting). Parent-reported disease severity should ideally be used in the form of a set of questions that is both easy to use, reproducible and reliable. The development of such a tool would empower both parents and clinicians, and could bridge to a certain extent the communication and knowledge gap between them.

\section{CONCLUSION}

This study presents an integral overview of what parents take into account when assessing disease severity in their child. Parents were very well able to describe disease severity of their children in terms of alternations in the child's normal characteristics. We identified a number of reassuring, general and alarming signs from the parents' perspective. Specific symptoms of disease like dehydration or dyspnoea were less easily described, especially if parents had no previous experience with these conditions. Future research should focus on the correlation between parent-reported symptoms and disease severity. Therefore, our next step will be to develop and validate a parent-reported disease severity tool that can help parents in the prehospital phase and during follow-up to predict disease severity and guide healthcare-seeking behaviour.

Contributors DLK performed and transcribed the semistructured interviews. DLK and NCB independently coded the transcripts. DP designed the study and contributed to the logistics. GJAD designed and supervised the study. JvdM and $\mathrm{RO}$ contributed to the design of the study. DLK and GJAD analysed the data and wrote the manuscript. DLP, NCB, JvdM, and R0 critically revised the manuscript. All authors approved the final manuscript.

Funding The authors have not declared a specific grant for this research from any funding agency in the public, commercial or not-for-profit sectors.

Competing interests None declared.

Patient consent for publication Not required.

Ethics approval This study received approval from the medical research ethics committee Zuidwest Holland and the local board of the Haga Teaching Hospital, Juliana Children's Hospital in the Hague (the Netherlands).

Provenance and peer review Not commissioned; externally peer reviewed.

Data availability statement Data are available upon reasonable request. Please contact GJAD (https://orcid.org/0000-0002-4566-9547).

Supplemental material This content has been supplied by the author(s). It has not been vetted by BMJ Publishing Group Limited (BMJ) and may not have been peer-reviewed. Any opinions or recommendations discussed are solely those of the author(s) and are not endorsed by BMJ. BMJ disclaims all liability and responsibility arising from any reliance placed on the content. Where the content includes any translated material, BMJ does not warrant the accuracy and reliability of the translations (including but not limited to local regulations, clinical guidelines, terminology, drug names and drug dosages), and is not responsible for any error and/or omissions arising from translation and adaptation or otherwise. 
Open access This is an open access article distributed in accordance with the Creative Commons Attribution Non Commercial (CC BY-NC 4.0) license, which permits others to distribute, remix, adapt, build upon this work non-commercially, and license their derivative works on different terms, provided the original work is properly cited, appropriate credit is given, any changes made indicated, and the use is non-commercial. See: http://creativecommons.org/licenses/by-nc/4.0/.

\section{ORCID iDs}

Daphne Peeters http://orcid.org/0000-0002-3110-9434

Josephine van de Maat http://orcid.org/0000-0001-7351-4596

Rianne Oostenbrink http://orcid.org/0000-0001-7919-8934

\section{REFERENCES}

1 Van den Bruel A, Bartholomeeusen S, Aertgeerts B, et al. Serious infections in children: an incidence study in family practice. BMC Fam Pract 2006;7:23.

2 Hay AD, Heron J, Ness A, et al. The prevalence of symptoms and consultations in pre-school children in the Avon longitudinal study of parents and children (ALSPAC): a prospective cohort study. Fam Pract 2005;22:367-74.

3 Peetoom K, Crutzen R, Dinant G-J, et al. Most preschool children with fever and common infection symptoms do not consult the family physician. Fam Pract 2019;36:371-3.

4 Bouwhuis CB, Kromhout MM, Twijnstra MJ. Geringe etnische verschillen in spoedeisende problemen bij kinderen: 10 jaar acute hulp in Het Sophia Kinderziekenhuis te Rotterdam. Ned Tijdschr Geneeskd 2001;145:1847-51.

5 Roukema J, Steyerberg EW, van der Lei J, et al. Randomized trial of a clinical decision support system: impact on the management of children with fever without apparent source. J Am Med Inform Assoc 2008;15:107-13.

6 Van den Bruel A, Haj-Hassan T, Thompson M, et al. Diagnostic value of clinical features at presentation to identify serious infection in children in developed countries: a systematic review. Lancet 2010;375:834-45.

7 Oostenbrink R, Nijman RG, Tuut MK. Richtlijn Koorts in de tweede lijn bij kinderen van 0 - 16 jaar. NVK, 2013.

8 Williams A, O'Rourke P, Keogh S. Making choices: why parents present to the emergency department for non-urgent care. Arch Dis Child 2009:94:817-20.

9 van lerland $Y$, Seiger $N$, van Veen $M$, et al. Self-referral and serious illness in children with fever. Pediatrics 2012;129:e643-51.

10 VERBI Software. MAXQDA 2020 [computer software]. Berlin Germany, 2019. Available: maxqda.com

11 van de Maat JS, van Klink D, den Hartogh-Griffioen A, et al. Development and evaluation of a hospital discharge information package to empower parents in caring for a child with a fever. BMJ Open 2018;8:e021697.

12 Walsh A, Edwards H, Fraser J. Influences on parents' fever management: beliefs, experiences and information sources. J Clin Nurs 2007;16:2331-40.

13 Van den Bruel A, Bruyninckx R, Vermeire E, et al. Signs and symptoms in children with a serious infection: a qualitative study. BMC Fam Pract 2005;6:36.

14 van der Werf ET, Redmond NM, Turnbull S, et al. Parental and clinician agreement of illness severity in children with RTIs: secondary analysis of data from a prospective cohort study. Br J Gen Pract 2019;69:e236-45.

15 Ingram J, Cabral C, Hay AD, et al. Parents' information needs, selfefficacy and influences on consulting for childhood respiratory tract infections: a qualitative study. BMC Fam Pract 2013;14:106.

16 Kelly M, Sahm LJ, Shiely F, et al. Parental knowledge, attitudes and beliefs regarding fever in children: an interview study. BMC Public Health 2016;16:540.

17 Sahm LJ, Kelly M, McCarthy S, et al. Knowledge, attitudes and beliefs of parents regarding fever in children: a Danish interview study. Acta Paediatr 2016;105:69-73.

18 Lagerløv P, Helseth S, Holager T. Childhood illnesses and the use of paracetamol (acetaminophen): a qualitative study of parents' management of common childhood illnesses. Fam Pract 2003;20:717-23.

19 Enarson MC, Ali S, Vandermeer B, et al. Beliefs and expectations of Canadian parents who bring febrile children for medical care. Pediatrics 2012;130:e905-12.

20 Kai J. What worries parents when their preschool children are acutely ill, and why: a qualitative study. BMJ 1996;313:983-6.

21 Van den Bruel A, Aertgeerts B, Bruyninckx R, et al. Signs and symptoms for diagnosis of serious infections in children: a prospective study in primary care. Br J Gen Pract 2007;57:538-46.

22 Hay AD, Redmond NM, Turnbull S, et al. Development and internal validation of a clinical rule to improve antibiotic use in children presenting to primary care with acute respiratory tract infection and cough: a prognostic cohort study. Lancet Respir Med 2016;4:902-10.

23 Blacklock C, Mayon-White R, Coad N, et al. Which symptoms and clinical features correctly identify serious respiratory infection in children attending a paediatric assessment unit? Arch Dis Child 2011;96:708-14.

24 Hewson $\mathrm{P}$, Poulakis Z, Jarman F, et al. Clinical markers of serious illness in young infants: a multicentre follow-up study. J Paediatr Child Health 2000;36:221-5.

25 Lee HN, Kwak YH, Jung JY, et al. Are parents' statements reliable for diagnosis of serious bacterial infection among children with fever without an apparent source?: A retrospective study. Medicine 2019;98:e17530.

26 Centaal Bureau voor de Statistiek. Standaard onderwijsindeling, 2017. Available: https://www.cbs.nl/-/media/pdf/2019/12/ pubsoi2016_ed1819.pdf 